\title{
Durable usage of patient-reported outcome measures in clinical practice to monitor health-related quality of life in head and neck cancer patients
}

\author{
S. Duman-Lubberding ${ }^{1}$ - C. F. van Uden-Kraan ${ }^{2}$ - F. Jansen ${ }^{1}$ - B. I. Witte ${ }^{3}$. \\ S. E. J. Eerenstein ${ }^{1}$. S. van Weert ${ }^{1} \cdot$ R. de Bree ${ }^{4}$ - C. R. Leemans ${ }^{1}$. \\ I. M. Verdonck-de Leeuw ${ }^{1,2}$
}

Received: 6 January 2017 / Accepted: 25 June 2017 / Published online: 12 July 2017

(C) The Author(s) 2017. This article is an open access publication

\begin{abstract}
Purpose To investigate the long-term follow-up (5 years) of implementing patient-reported outcome measures (PROMs) in clinical practice to monitor health-related quality of life (HRQOL) in head and neck cancer (HNC) patients.

Methods A mixed method design was used. The usage rate of OncoQuest (a touch screen computer system to monitor HRQOL) and the subsequent nurse consultation was calculated among HNC patients who visited the outpatient clinic for regular follow-up, as well as differences between ever users and never users (sociodemographic and clinical characteristics). The content of the nurse consultation was investigated. Reasons for not using (barriers) or using (facilitators) OncoQuest and the nurse consultation were explored from the perspective of HNC patients, and of head and neck surgeons.

Results Usage rate of OncoQuest was $67 \%$ and of the nurse consultation 79\%. Usage of OncoQuest was significantly related to tumor subsite and tumor stage. Topics most frequently $(>40 \%$ ) discussed during the nurse consultation were global quality of life (97\%), head and neck cancer related symptoms (82\%), other physical symptoms such as pain $(61 \%)$, and
\end{abstract}

I. M. Verdonck-de Leeuw im.verdonck@vumc.nl

1 Department of Otolaryngology/Head and Neck Surgery, VU University Medical Center, P.O. Box 7057, 1007 MB Amsterdam, The Netherlands

2 Clinical Psychology, VU University, Amsterdam, The Netherlands

3 Epidemiology and Biostatistics, VU University Medical Center, Amsterdam, The Netherlands

4 Cancer center, University Medical Center Utrecht, Utrecht, The Netherlands psychological problems such as anxiety (44\%). Several barriers and facilitators to implement PROMs in clinical practice were reported by both patients and head and neck surgeons. Conclusion Usage of PROMs in clinical practice and a nurse consultation is durable, even 5 years after the introduction. This study contributes to better insight into long-term follow-up of implementation, thereby guiding future research and projects that aim to implement PROMs in clinical practice to monitor HRQOL among (head and neck) cancer patients.

Keywords Head and neck cancer · Patient-reported outcome measures $\cdot$ Screening for psychological distress ·

Implementation $\cdot$ Health-related quality of life

\section{Introduction}

In clinical practice, monitoring health-related quality of life (HRQOL) can be helpful to identify cancer patients with problems, concerns, and needs [1-3]. The use of patient-reported outcome measures (PROMs) to monitor HRQOL is feasible and acceptable [4]. Using PROMs allows patients to actively participate in their own care by providing the information they know best and helps clinicians to identify patients' most bothersome issues [3, 5-7]. However, because monitoring alone does not improve patients' HRQOL [8,9], this needs to be followed by providing individual feedback to the patient and the healthcare provider (HCP) so they can discuss the need for supportive care [10-16]. In addition, collecting HRQOL data by means of PROMS in daily clinical practice is of high importance for research purposes also. PROMs provide data which are unique in detaining the patient's own view on the impact of having cancer, and its treatment, on their HRQOL. 
Based on the existing evidence, several evidence-based national guidelines recommend routine HRQOL assessment in clinical practice [e.g., 17-21]. Although the importance of monitoring HRQOL in clinical practice is clearly recognized, it remains difficult to implement PROMs in clinical practice. Previous studies showed that following the implementation, usage rates vary from 40 to $73 \%$ [22-24]. These results are based on short-term follow-up studies investigating the success of implementation. Knowledge on the long-term implementation is lacking $[4,7]$.

In 2006, we introduced a computer-assisted PROMs system (OncoQuest) in our clinical practice to monitor HRQOL among head and neck cancer (HNC) patients. Usage rate of OncoQuest in the first year after implementation was $67 \%$ [22]. To increase usage rate and the relevance of monitoring HRQOL for the individual patient, from 2008 onwards, we have been using OncoQuest in combination with a nurse consultation.

The overall aim of the present study was to investigate the long-term follow-up of OncoQuest and the nurse consultation, 5 years after the implementation. We investigated the current usage rate of OncoQuest and the nurse consultation among HNC patients, as well as differences between ever users and never users (sociodemographic and clinical characteristics) (aim A). Furthermore, we investigated the content of the nurse consultation (aim B). Also, we explored reasons for not using (barriers) or using (facilitators) OncoQuest and the nurse consultation from the perspective of HNC patients (aim C) and from the perspective of the head and neck surgeons (aim D). This study contributes to better insight into long-term followup of implementation.

\section{Methods}

A mixed methods design was used, with quantitative and qualitative research methods. The study was conducted at the Department of Otolaryngology - Head and Neck Surgery, VU University Medical Center in Amsterdam, The Netherlands, between April 2013 and September 2013. According to the Dutch Medical Research Involving Human Subjects Act, ethical approval was not necessary, because this study evaluated regular care and patients were not subjected to procedures or required to follow rules of behavior.

\section{Description of OncoQuest and the nurse consultation}

All HNC patients who are treated with curative intent are offered to use OncoQuest to monitor HRQOL via the EORTC QLQ-C30 and QLQ-H\&N35 questionnaires and the Hospital Anxiety and Depression Scale (HADS) (in total 79 items), and to discuss the results by consulting an oncology nurse during follow-up visits after cancer treatment. Patients are also asked permission to use their HRQOL data in OncoQuest for research purposes. OncoQuest is available on dedicated computers with a touch screen in a separate consultation room. Due to logistic reasons, patients fill in OncoQuest after the followup visit with their surgeon. When a patient has completed OncoQuest, he or she can discuss the results with the nurse. The results of OncoQuest are available in real time in clear graphics on a computer screen by means of a stand-alone application (OncoQuest viewer), which is linked to the hospital information system. Based on the results, the nurse can identify and support HNC patients with problems regarding HRQOL or psychological distress. In this nurse consultation, the nurse provides information and advice, and, if needed, supportive care options are discussed. Usage is on a voluntary basis.

\section{Aim A: usage rate of OncoQuest and nurse consultation, and differences between ever users and never users}

To determine the usage rate of OncoQuest, the number of patients who ever used OncoQuest was divided by the number of all eligible HNC patients. The number of eligible HNC patients (denominator) was counted by reviewing data of patients (all subsites, all stages) who were treated with curative intent (all treatment modalities) at least 3 months earlier and who attended the outpatient clinic during the study period (April-September 2013) through the hospital information system. Patients' usage data - if they used OncoQuest and the number of times they used OncoQuest - was consequently derived from the OncoQuest database. We defined patients as an ever user of OncoQuest if they had used OncoQuest during at least one follow-up visit. We did not limit the usage to the study period, since patients visiting the outpatient clinic are at different stages of their follow-up and could therefore have used OncoQuest in the past.

To determine the usage rate of the nurse consultation, the number of patients who used the nurse consultation during the study period was divided by the number of all patients who used OncoQuest during the study period (current users). We limited the usage of the nurse consultation to the study period, since information on usage of the nurse consultation was not collected earlier.

To gain insight into the characteristics of ever users, current users, and never users of OncoQuest and the nurse consultation, sociodemographic (age, sex) and clinical variables (tumor location, tumor stage, and type of treatment) were obtained from the medical records.

\section{Aim B: content of the nurse consultation}

To gain insight into the content of the nurse consultation following the use of OncoQuest, a researcher observed all nurse 
consultations during the study period with patients' consent and filled out a study-specific report form. In this report form, the researcher noted the length of the consultation, the topics that were discussed, and the advice and supportive care options provided by the nurse.

\section{Aim C: barriers and facilitators}

To gain insight into barriers to use OncoQuest and the nurse consultation, a random sample of patients who did not use OncoQuest and the nurse consultation during the current follow-up visit (nonusers), were asked about their reasons. A researcher posted at the consultation room of one of the six head and neck surgeons (based on a circulation scheme). Patients who did not proceed to OncoQuest were approached by the researcher for a short structured interview with predefined answer categories. The researcher asked patients for their reasons for nonuse of OncoQuest and the nurse consultation, as well as for their suggestions on improvement. The researcher noted the answer as provided by the patient. In addition, the researcher noted the respondents' sociodemographic variables sex and date of birth. Information regarding the number of times patients used OncoQuest ever before the current follow-up visit was derived from the OncoQuest database.

To gain insight into facilitators to use OncoQuest and the nurse consultation, we asked all patients who used OncoQuest and the nurse consultation during the study period (current users) to complete and return a study-specific paper-andpencil questionnaire. The questionnaire included two questions on age and sex, and four items with predefined answer options (comparable to the questions asked in the interviews with nonusers) regarding reasons to use and added value of OncoQuest and the nurse consultation. Patients were able to choose multiple answers and were invited to elaborate by means of a free-text response. Information regarding the number of times patients had used OncoQuest before the current follow-up visit was derived from the OncoQuest database.

To evaluate patients' satisfaction with the nurse consultation, the questionnaire contained three questions on satisfaction with this consultation. General satisfaction was measured with the Net Promotor Score (NPS) with the question "How likely is it that you would recommend the nurse's consultation to other cancer patients (11-point rating scale: 0 (not likely) to 10 (very likely)). The NPS is calculated by subtracting the percentage of detractors (that score $0-6$ ) from the percentage of promotors (that score 9-10). The percentages "passives" that score 7-8 is not included in calculating the NPS. The range of the NPS lies between -100 and +100 . A positive score is considered good [25]. Additionally, patients were asked how satisfied they were with respect to the knowledge of the nurse regarding supportive care options, and with respect to her listening skills (11-point rating scales).
Aim D: exploring the perspective of the head and neck surgeons

Semistructured interviews were conducted with the head and neck surgeons involved in follow-up visits $(N=6)$. Interviews included questions concerning the added value and barriers of OncoQuest and the nurse consultation, and recommendations for improvement.

\section{Data analyses}

All statistical analyses were performed using the IBM Statistical Package for the Social Sciences (SPSS) version 22 (IBM Corp. Armonk, NY, USA). For aim A, descriptive statistics were used to describe sociodemographic and clinical characteristics of ever users and never users, as well as the number of times OncoQuest was used. We conducted chisquare tests, independent sample $t$-tests, and multiple logistic regression analyses to study demographic (age, sex) and clinical variables (tumor subsite, stage, and treatment modality) in relation to usage of OncoQuest and the nurse consultation. A multiple logistic regression model, with a stepwise forward selection procedure, was applied. Variables were added one by one to the multiple regression model, with $p$ value for entry $p<0.1 . p$ values $<0.05$ were considered statistically significant.

For aim B, descriptive statistics were used to describe the characteristics of the nurse's consultation. For aim $\mathrm{C}$, the answers provided by the patients during the interviews on nonusage were categorized into one of the predefined answer categories. If the answer did not match one of the predefined answer categories, these reasons for nonusage and suggestions for improvement were added. Descriptive statistics were used to summarize reasons, suggestions for improvement, and the number of times these patients had used OncoQuest in the past, and to summarize the facilitators identified in the questionnaire and patients' satisfaction with the consultation.

For aim D, the semistructured interviews were analyzed by thematic analyses.

\section{Results}

\section{Aim A: usage rate}

During the study period of 6 months, 449 patients who visited the outpatient clinic for their follow-up visits fulfilled the inclusion and exclusion criteria (all eligible HNC patients). The characteristics of these patients are shown in Table 1. Of these patients, 303 were defined as an ever user of OncoQuest. To calculate the usage rate of OncoQuest, the number of OncoQuest ever users was divided by all eligible HNC patients (303/449). The usage rate of OncoQuest was 67\%, 
Table 1 Characteristics of the total study population $(N=449)$ and differences between ever users and never users of OncoQuest

\begin{tabular}{|c|c|c|c|}
\hline & Total, $N=449$ & Ever users, $N=303$ & Never users, $N=146$ \\
\hline \multicolumn{4}{|l|}{$\operatorname{Sex}(N, \%)$} \\
\hline Male & 312 & $205(68 \%)$ & $107(73 \%)$ \\
\hline Female & 137 & $98(32 \%)$ & $39(27 \%)$ \\
\hline \multicolumn{4}{|l|}{ Age in years } \\
\hline Mean (SD) & $63.5(10.4)$ & $62.9(10.3)$ & $64.9(10.5)$ \\
\hline \multicolumn{4}{|l|}{ Tumor site $(N, \%)$} \\
\hline Pharynx & 165 & $121(40 \%)$ & $44(30 \%)$ \\
\hline Larynx & 141 & $77(25 \%)$ & $64(44 \%)$ \\
\hline Oral cavity & 117 & $85(28 \%)$ & $32(22 \%)$ \\
\hline Other & 26 & $20(7 \%)$ & $6(4 \%)$ \\
\hline \multicolumn{4}{|l|}{ Tumor stage $(N, \%)^{\mathrm{a}}$} \\
\hline 1 & 139 & $75(27 \%)$ & $64(51 \%)$ \\
\hline 2 & 65 & $49(17 \%)$ & $16(13 \%)$ \\
\hline 3 & 54 & $43(15 \%)$ & $11(9 \%)$ \\
\hline 4 & 149 & $114(41 \%)$ & $35(27 \%)$ \\
\hline \multicolumn{4}{|l|}{ Type of treatment $(N, \%)^{\mathrm{b}}$} \\
\hline Surgery & 128 & $70(23 \%)$ & $58(40 \%)$ \\
\hline (Chemo)radiation & 238 & $169(56 \%)$ & $69(48 \%)$ \\
\hline Surgery and (chemo)radiation & 83 & $64(21 \%)$ & $19(13 \%)$ \\
\hline
\end{tabular}

meaning that $67 \%$ of the patients used OncoQuest at least once post-treatment. OncoQuest ever users used it between 1 and 11 times after treatment (median 2, interquartile range (IQR) 1-3).

Multivariate analyses showed that tumor stage and subsite were significantly associated with the use of OncoQuest. Patients treated for a tumor stage $>$ I used OncoQuest relatively more often, and patients treated for a tumor stage I used OncoQuest relatively less often. Patients with laryngeal cancer used OncoQuest relatively less often compared to other head and neck subsites (Table 2).

During the study period of 6 months, 147 patients used OncoQuest at the time of their follow-up visit (current users), of which 116 (out of 147) also used the nurse consultation (usage rate 79\%) (Table 3). Age, sex, tumor subsite, tumor stage, and treatment modality were not significantly related to the use of the nurse consultation.

\section{Aim B: content of the nurse consultation}

Reports of the nurse consultations were available for 113/ 116 patients. In three cases, there was no report due to logistic reasons. The consultations lasted 2 to $30 \mathrm{~min}$ (median $10 \mathrm{~min}$, IQR 7-13 $\mathrm{min}$ ). Topics most frequently ( $>40 \%$ ) discussed during the consultation included global quality of life (97\%); head and neck cancer related symptoms such as speech, swallowing, and oral dysfunction
(82\%); other physical symptoms such as fatigue and pain (61\%); anxiety (44\%); and depression (41\%). The nurse provided practical advice in $23 \%$ of the consultations. This advice comprised information on how to cope with current physical or psychological sequelae of cancer and its treatment. In $11 \%$ of the consultations, patients received information on, e.g., the website of the Dutch Cancer Society, relevant books, or brochures. Also, 11\%

Table 2 Multiple logistic regression analysis of significant variables of usage of OncoQuest in the total study population $(N=407)$

\begin{tabular}{llll}
\hline & OR & $95 \%$ CI & $p$ value \\
\hline $\begin{array}{l}\text { Tumor stage } \\
\text { Stage 1 }\end{array}$ & 1.0 & & $p=0.001$ \\
Stage 2 & 2.6 & $1.3-5.2$ & \\
Stage 3 & 3.3 & $1.5-7.0$ & \\
Stage 4 & 2.4 & $1.4-4.3$ & \\
Tumor site & & & \\
Larynx & 1.0 & & \\
Pharynx & 1.9 & $1.0-3.3$ & \\
Oral cavity & 2.1 & $1.2-3.7$ & \\
Other & 3.3 & $1.1-9.7$ & \\
\hline
\end{tabular}

Age, sex, and treatment modality were not significantly associated with usage rate, and therefore not included in these analyses. Number of patients in these analyses is smaller $(N=407)$ than the total study population $(N=449)$ because of missing data on tumor stage 
Table 3 Characteristics of current users (patients who used OncoQuest during the study period) $(N=147)$, and differences between users and nonusers of the nurse consultation

\begin{tabular}{llll}
\hline & Total, $N=147$ & Users, $N=116$ & Nonusers, $N=31$ \\
\hline $\begin{array}{l}\text { Sex }(N, \%) \\
\text { Male }\end{array}$ & 95 & $76(66 \%)$ & $19(61 \%)$ \\
$\quad$ Female & 52 & $40(34 \%)$ & $12(39 \%)$ \\
Age in years & & & \\
$\quad$ Mean (SD) & $62.9(10.4)$ & $62.2(10.2)$ & $65.8(11.1)$ \\
Tumor site $(N, \%)$ & & & $13(42 \%)$ \\
Pharynx & 53 & $40(34 \%)$ & $8(26 \%)$ \\
Larynx & 30 & $22(19 \%)$ & $4(13 \%)$ \\
Oral cavity & 32 & $28(24 \%)$ & $6(19 \%)$ \\
Other & 32 & $26(22 \%)$ & $3(11 \%)$ \\
Tumor stage $(N, \%)^{\mathrm{a}}$ & & & $7(26 \%)$ \\
1 & 28 & $25(23 \%)$ & $5(19 \%)$ \\
2 & 32 & $25(23 \%)$ & $12(44 \%)$ \\
3 & 27 & $22(21 \%)$ & $8(26 \%)$ \\
4 & 47 & $35(33 \%)$ & $17(55 \%)$ \\
Type of treatment $(N, \%)$ & & & $6(19 \%)$ \\
Surgery & 34 & $26(22 \%)$ & \\
$($ Chemo)radiation & 62 & $45(39 \%)$ & \\
Surgery and (chemo)radiation & 51 & & \\
\hline
\end{tabular}

${ }^{\text {a }}$ Data on tumor stage is missing in 13 patients of patients were referred to peer support, including patient societies or a community center for cancer patients.

\section{Aim C: barriers and facilitators to use OncoQuest and the nurse consultation}

\section{Barriers}

In total, $84 \mathrm{HNC}$ patients who did not use OncoQuest at the current follow-up visit were asked to participate in a short structured interview. Two patients did not want to participate, and one was mentally challenged and unable to answer questions. Ten patients indicated that they were not interested in OncoQuest with no further explanation. The majority of the remaining 71 patients were male $(N=52,73 \%)$, and their mean age was 66 years old (range 42-87, SD 9.9). Of these 71 patients, $42(59 \%)$ had used OncoQuest at, least one follow-up visit in the past (ever users), and 29 patients $(41 \%)$ were never users. Most mentioned reasons for not using OncoQuest were lack of time $(N=29,41 \%)$ and that patients did not have supportive care related questions $(N=14,20 \%)$ (Table 4). Suggestions to improve OncoQuest that were mentioned during the interviews related mostly to the user-friendliness, e.g., tailor the questions to the individual patient and limit the number of questions. Patients also mentioned that it would be helpful to have a better explanation of OncoQuest at the start of treatment, and it would be nice to receive feedback during their consultation with the head and neck surgeon.

\section{Facilitators}

In total, 112 (out of 116) patients who used OncoQuest and the nurse consultation during the study period received a studyspecific questionnaire, of which 83 completed the questionnaire. The majority was male $(N=57,69 \%)$, and the mean age was 62 years old (SD 10.2, range 24-87). Most frequent reasons to use OncoQuest were that patients were asked by their $\operatorname{HCP}(N=71,86 \%)$, and that patients wanted to contribute to scientific research $(N=34,41 \%)$ (Table 5$)$. Most frequently mentioned reasons regarding the added value of OncoQuest were that changes in symptoms and HRQOL over time are monitored $(N=61,73 \%)$, and that symptoms are adequately addressed $(N=39,47 \%)$. Also, some mentioned that by using OncoQuest, they had a clearer overview of what they wanted to ask their $\mathrm{HCP}(N=4,5 \%)$. Free text responses yielded no additional reasons to use OncoQuest.

With respect to the nurse consultation, the most frequent reasons for usage was being asked to do so $(N=71,86 \%)$ and the opportunity to talk with the nurse $(N=21,25 \%)$ (Table 5$)$. Free text responses yielded additional reasons including seeing the nurse's consultation as an automatic consequence following the use of OncoQuest, and a personal and friendly way to discuss the results. As added value of the nurse consultation, patients mentioned the amount of time the consulting nurse had to discuss the OncoQuest results $(N=61,74 \%)$, the personal conversation and advice $(N=29,35 \%)$, and obtaining answers to questions regarding their disease, 
Table 4 Barriers for using OncoQuest $(N=71)$

\begin{tabular}{llll}
\hline & $\begin{array}{l}\text { Total }(N=71), \\
N(\%)\end{array}$ & $\begin{array}{l}\text { Ever users }^{\mathrm{a}} \\
(N=42), N(\%)\end{array}$ & $\begin{array}{l}\text { Never users } \\
(N=29), N(\%)\end{array}$ \\
\hline Lack of time & $29(41)$ & $15(36)$ & $14(48)$ \\
No questions regarding supportive care & $14(20)$ & $10(24)$ & $4(14)$ \\
No change in symptoms & $10(14)$ & $9(21)$ & $1(3)$ \\
No need & $10(14)$ & $4(11)$ & $6(21)$ \\
No added value & $7(10)$ & $5(12)$ & $2(7)$ \\
Emotional problems & $6(8)$ & $5(12)$ & $1(3)$ \\
Participation in other scientific research & $4(6)$ & $2(5)$ & $2(7)$ \\
Filled out a similar questionnaire at another department & $2(3)$ & $1(2)$ & $1(3)$ \\
Parking fee is getting too high/ticket & $2(3)$ & $2(5)$ & - \\
$\quad$ expires & $2(3)$ & - & $2(7)$ \\
Not wanting to use a computer & $13(18)$ & $8(19)$ & $5(17)$ \\
Miscellaneous & & & \\
\hline
\end{tabular}

Seventy-one patients did not use OncoQuest at the current follow-up visit (multiple answers possible)

${ }^{\text {a }}$ Forty-two patients who used OncoQuest at a previous follow-up visit, but not at the current follow-up visit

${ }^{\mathrm{b}}$ Twenty-nine patients who did not use OncoQuest at the present or a previous follow-up visit
HRQOL, and symptoms $(N=13,16 \%)$. Overall, patients were satisfied with the nurse consultation, with a Net Promotor Score of 25 . The majority highly valued the listening skills of the nurse (11-point scale: median 9, IQR 8-10) and the knowledge of available supportive care (11-point scale: median 8, IQR 8-10).

\section{Aim D: perspective of head and neck surgeons}

All six interviewed head and neck surgeons stressed the importance of OncoQuest and the nurse consultation for patients during the follow-up period after treatment. Several themes were mentioned concerning the added value of OncoQuest in clinical practice (Table 6). Also, several barriers were

Table 5 Facilitators to use OncoQuest and the nurse consultation $(N=83)$

\begin{tabular}{lll}
\hline & Number & Percent \\
\hline OncoQuest & 71 & 86 \\
Being asked by staff & 34 & 41 \\
Contributing to scientific research & 6 & 7 \\
Monitoring changes in quality of life & 5 & 6 \\
Expecting to benefit from using OncoQuest & & \\
Nurse consultation & 71 & 86 \\
Being asked by staff & 21 & 25 \\
Appreciating the conversation with the nurse & 10 & 12 \\
Wanting to discuss results OncoQuest & 9 & 11 \\
Nurse has more time than physician & 3 & 4 \\
Wanting to share their story with the nurse & 1 & 1 \\
Having a question for the nurse & \\
\hline
\end{tabular}

Eighty-three patients who did use OncoQuest and the nurse consultation at the current follow-up visit (multiple answers possible) mentioned, like a lack of feedback from the surgeon to the patient on the results of OncoQuest may lead to a decrease in patient's motivation to use OncoQuest, and using OncoQuest takes too much time according to their patients. Finally, head and neck surgeons mentioned several improvements that could possibly eliminate these barriers, for example, the provision of feedback to the physician within the electronic patient file (instead of via a standalone application) and enhanced accessibility of OncoQuest for patients (e.g., ability for patients to access OncoQuest online from home) (Table 6).

\section{Discussion}

The main aim of this study was to investigate the usage of PROMS in clinical practice through a computer-assisted PROMs system "OncoQuest" combined with a nurse consultation, 5 years after the introduction. Study results are discussed within the scope of the RE-AIM framework. The RE-AIM framework is designed to enhance the quality, speed, and public health impact of efforts to translate research into practice and can be used to study the reach, effectiveness, adoption, implementation, and maintenance of healthcare innovations [26].

In this study, we investigated the reach of OncoQuest and the nurse consultation by comparing ever users and never users. The usage rate of OncoQuest remained 67\%, the same as at the time of the introduction [22]. This high usage rate, even in the long term, might be explained due to the fact that OncoQuest is combined with a nurse consultation. Among the patients who used OncoQuest, the majority also used the nurse consultation (79\%). Other explanations based on our study 
Table 6 Facilitators, barriers, and suggestions for improvement according to head and neck surgeons $(N=6)$

\begin{tabular}{|c|c|}
\hline Interview topics & Themes \\
\hline $\begin{array}{l}\text { Facilitators of OncoQuest and the nurse } \\
\text { consultation }\end{array}$ & $\begin{array}{l}\text { - An enhanced insight into patients' HRQOL } \\
\text { - A signaling function for symptoms missed in follow-up } \\
\text { consultations } \\
\text { - Attention for a wide range of symptoms and concerns (including } \\
\text { psychosocial issues) } \\
\text { - The possibility to improve (timely) referral to supportive care } \\
\text { tailored to individual patients' needs } \\
\text { - The opportunity to offer increased (profound) attention to } \\
\text { patients } \\
\text { - Offering patients the opportunity to have their story heard }\end{array}$ \\
\hline $\begin{array}{l}\text { Barriers of OncoQuest and the nurse } \\
\text { consultation }\end{array}$ & $\begin{array}{l}\text { - Not all patients have a need for OncoQuest (at each follow-up } \\
\text { consultation) } \\
\text { - The value of repeated use is not clear to patients } \\
\text { - Using OncoQuest takes too much time according to their patients } \\
\text { - The availability of OncoQuest outcomes during consultation is } \\
\text { hampered due to difficulties to trace OncoQuest results at their } \\
\text { computer screen } \\
\text { - Patients use OncoQuest after the follow-up visit (due to logistic } \\
\text { reasons) } \\
\text { - A lack of feedback from the surgeon to the patient on the results } \\
\text { of OncoQuest may lead to a decrease in patient's motivation to } \\
\text { use OncoQuest } \\
\text { - Patients' usage of OncoQuest after the follow-up visit to the } \\
\text { surgeon (due to logistic reasons) leads to a lack of (accurate) } \\
\text { feedback from the surgeon to the patient and to a possible delay } \\
\text { in referral to supportive care } \\
\text { - OncoQuest may address unsolvable problems (e.g. dry mouth, } \\
\text { swallowing problems) possibly leading to a decrease in patients' } \\
\text { motivation to use OncoQuest } \\
\text { - A lack of structural feedback to the surgeon from what is } \\
\text { discussed during the nurse consultation }\end{array}$ \\
\hline $\begin{array}{l}\text { Suggestions for improvement of } \\
\text { OncoQuest and the nurse consultation }\end{array}$ & $\begin{array}{l}\text { - Provision of feedback to the physician within the electronic } \\
\text { patient file (instead of via a standalone application) } \\
\text { - The provision of extra reminders for physicians during } \\
\text { consultation hours so they remember to discuss patients' results } \\
\text { - Enhanced accessibility of OncoQuest for patients (e.g., ability for } \\
\text { patients to access OncoQuest online from home) }\end{array}$ \\
\hline
\end{tabular}

data might be that the HCPs at the outpatient clinic personally invite patients to make use of OncoQuest and patients' awareness of usage of OncoQuest data for research purposes also. This suggests that trust, therapeutic alliance, and altruism, as in helping other patients by participating in scientific research, might increase durable participation in monitoring HRQOL by means of PROMS in clinical practice. Usage rate of OncoQuest was significantly related to tumor stage. Patients treated for a tumor stage >I used OncoQuest relatively more often and patients with a tumor stage I used OncoQuest relatively less often. It may be that the never users have a lower need for supportive care and therefore are not likely to use OncoQuest and the nurse consultation.

Although we did not perform a randomized controlled trial on the effectiveness, study results showed that current users were very satisfied and most would recommend OncoQuest and the nurse consultation. HRQOL following cancer treatment was monitored via OncoQuest, and important issues to patients were discussed with the nurse. Patients felt that the nurse truly listened to their concerns and indicated to have faith in the referrals and advice given. These findings confirm earlier studies on the value of using PROMs in clinical practice to improve communication between patients and HCPs [4, 6], to identify cancer patients' most bothersome issues [3], to monitor the course of symptoms as swallowing problems [27, 28], and to facilitate screening for psychological distress [2].

With respect to the adoption by care providers, all head and neck surgeons were satisfied with the use of PROMs in clinical practice and the nurse consultation. This high adoption rate by surgeons was important also for patients since our 
study results showed that one of the facilitators for patients to use OncoQuest and the nurse consultation was to be referred by their HCP. Adoption by HCPs is a key issue in implementing new interventions in cancer care $[4,29]$.

In this study, we explored barriers and facilitators of using OncoQuest and the nurse consultation. Finding the optimal way to implement PROMs in clinical practice is difficult and often creates logistical challenges $[15,30,31]$. In line with previous studies [15], patients in our study mentioned several barriers, such as no change in symptoms since the previous follow-up visit, and no need for supportive care. To overcome these barriers, we decided 5 years ago that using OncoQuest and the nurse consultation is on a voluntary basis, so that patients can decide themselves whether or not to use this service. This decision in favor of user-friendliness, does, however, hamper us to use the HRQOL data for research purposes.

Finally, this study provided insight into the maintenance of OncoQuest and the nurse consultation among HNC patients. Although the results are positive and usage rate was high, maintenance remains a challenge and needs regular reevaluation. For instance, in our hospital, a new electronic hospital information system was introduced last year, and we are still busy incorporating OncoQuest into this new system.

A strength of this study is that we involved all stakeholders to study the long-term follow-up of OncoQuest and nurse consultation. A weakness is that we did not use the RE-AIM framework upfront to define outcome measures as well as process indicators to study the long-term implementation. In addition, there is a potential bias in comparing the usage rate of OncoQuest as determined in the current study, compared to the usage rate as determined in the first year after implementation of OncoQuest, resulting from differences in study cohorts. Future research is needed to obtain more insights into the uptake of supportive care services after using OncoQuest and the nurse consultation. The likelihood of supportive care uptake by patients is increased when there is a good relationship between the patient and the team of HCPs [32]. Implementing PROMs in clinical practice facilitates this good relationship. OncoQuest is now used in follow-up care and not yet in patients during treatment. The reason is that patients during treatment already have frequent contact with their HCPs. However, an adapted version of OncoQuest specifically targeting patients during treatment may have added value as well, but further research is needed to explore the needs of both patients and HCPs for OncoQuest during treatment. Another area of further research is to provide patients the opportunity to fill out PROMs at home before their followup visit. Via an online system, the uptake of using PROMs may be increased. The online use of PROMs at home seems to be feasible for a large percentage of cancer patients [33, 34]. This could lead to a better preparation for clinical consultations and a better adherence to medical advice [35], possibly including a better uptake of supportive care services.

\section{Conclusion}

The majority of HNC patients use PROMs and a nurse consultation in clinical practice, also in the long term. This study contributes to better insight into durable usage of PROMs, thereby guiding future research and other projects that aim to implement PROMs in clinical practice to monitor HRQOL among (head and neck) cancer patients.

Acknowledgements We would like to thank Inge Braspenning, Yvonne Cruijff, Ton Houffelaar, Laura Korsten, Heleen Melissant, Annette van Nieuwenhuizen, Mathilde Pronk, and Valesca van Zwieten for their contributions to this study.

\section{Compliance with ethical standards}

Conflict of interest The authors declare that they have no conflict of interest.

Open Access This article is distributed under the terms of the Creative Commons Attribution-NonCommercial 4.0 International License (http:// creativecommons.org/licenses/by-nc/4.0/), which permits any noncommercial use, distribution, and reproduction in any medium, provided you give appropriate credit to the original author(s) and the source, provide a link to the Creative Commons license, and indicate if changes were made.

\section{References}

1. Grassi L, Caruso R, Sabato S, Massarenti S, Nanni MG, The UniFe Psychiatry Working Group Coauthors (2015) Psychosocial screening and assessment in oncology and palliative care settings. Front Psychol 5:1485. doi:10.3389/fpsyg.2014.01485

2. Krebber A-MH, Jansen F, Cuijpers P, Leemans CR, Verdonck-de Leeuw IM (2016) Screening for psychological distress in follow-up care to identify head and neck cancer patients with untreated distress. Support Care Cancer 24:2541-2548. doi:10.1007/s00520015-3053-6

3. Snyder CF, Blackford AL, Aaronson NK, Detmar SB, Carducci MA, Brundage MD et al (2011) Can patient-reported outcome measures identify cancer patients' most bothersome issues? J Clin Oncol 29:1216-1220. doi:10.1200/JCO.2010.33.2080

4. Wintner LM, Sztankay M, Aaronson N, Bottomley A, Giesinger JM, Groenvold M et al (2016) The use of EORTC measures in daily clinical practice - a synopsis of a newly developed manual. Eur J Cancer 68:73-81. doi:10.1016/j.ejca.2016.08.024

5. Bennett AV, Jensen RE, Basch E (2012) Electronic patient-reported outcome systems in oncology clinical practice. CA Cancer J Clin 62:336-347. doi:10.3322/caac. 21150

6. Kotronoulas G, Kearney N, Maguire R, Harrow A, Di Domenico $\mathrm{D}$, Croy S et al (2014) What is the value of the routine use of patient-reported outcome measures toward improvement of patient outcomes, processes of care, and health service outcomes in cancer care? A systematic review of controlled trials. J Clin Oncol 32: 1480-1501. doi:10.1200/JCO.2013.53.5948

7. Warrington L, Absolom K, Velikova G (2015) Integrated care pathways for cancer survivors - a role for patient-reported outcome measures and health informatics. Acta Oncol 54:600-608. doi:10. 3109/0284186X.2014.995778 
8. Coyne JC (2013) Benefits of screening cancer patients for distress still not demonstrated. Br J Cancer 108:736-737. doi:10.1038/bjc. 2013.16

9. Palmer SC, van Scheppingen C, Coyne JC (2011) Clinical trial did not demonstrate benefits of screening patients with cancer for distress. J Clin Oncol 29:e277-e278. doi:10.1200/JCO.2010.34.1206

10. Velikova G, Booth L, Smith AB, Brown PM, Lynch P, Brown JM et al (2004) Measuring quality of life in routine oncology practice improves communication and patient well-being: a randomized controlled trial. J Clin Oncol 22:714-724. doi:10.1200/JCO.2004. 06.078

11. Carlson LE, Waller A, Mitchell AJ (2012) Screening for distress and unmet needs in patients with cancer: review and recommendations. J Clin Oncol 30:1160-1177. doi:10.1200/JCO.2011.39.5509

12. Carlson LE, Waller A, Groff SL, Zhong L, Bultz BD (2012) Online screening for distress, the 6th vital sign, in newly diagnosed oncology outpatients: randomised controlled trial of computerised vs personalised triage. Br J Cancer 107:617-625. doi:10.1038/bjc. 2012.309

13. Mitchell AJ (2010) Short screening tools for cancer-related distress: a review and diagnostic validity meta-analysis. J Natl Compr Cancer Netw 8:487-494

14. Mitchell AJ (2013) Screening for cancer-related distress: when is implementation successful and when is it unsuccessful? Acta Oncol (Madr) 52:216-224. doi:10.3109/0284186X.2012.745949

15. Howell D, Molloy S, Wilkinson K, Green E, Orchard K, Wang K et al (2015) Patient-reported outcomes in routine cancer clinical practice: a scoping review of use, impact on health outcomes, and implementation factors. Ann Oncol 26:1846-1858. doi:10.1093/ annonc/mdv181

16. Funk R, Cisneros C, Williams RC, Kendall J, Hamann HA (2016) What happens after distress screening? Patterns of supportive care service utilization among oncology patients identified through a systematic screening protocol. Support Care Cancer. doi:10.1007/ s00520-016-3099-0

17. German cancer society (Deutsche Krebbsgesellschaft). Clinical practice guidelines. n.d. http://www.krebsgesellschaft.de/gcs/ german-cancer-society/guidelines.html

18. Adler NE, Stead WW (2015) Patients in context-EHR capture of social and behavioral determinants of health. N Engl J Med 372: 698-701. doi:10.1056/NEJMp1413945

19. Andersen BL, DeRubeis RJ, Berman BS, Gruman J, Champion VL, Massie MJ et al (2014) Screening, assessment, and care of anxiety and depressive symptoms in adults with cancer: an American Society of Clinical Oncology guideline adaptation. J Clin Oncol 32:1605-1619. doi:10.1200/JCO.2013.52.4611

20. Association of Comprehensive Cancer Centres (ACCC) [Internet]. Oncoline cancer clinical practice guidelines. 2015. http://www. oncoline.nl/index.php

21. Fashoyin-Aje LA, Martinez KA, Dy SM (2012) New patientcentered care standards from the commission on cancer: opportunities and challenges. J Support Oncol 10:107-111. doi:10.1016/j. suponc.2011.12.002

22. de Bree R, Verdonck-de Leeuw IM, Keizer AL, Houffelaar A, Leemans CR (2008) Touch screen computer-assisted health-related quality of life and distress data collection in head and neck cancer patients. Clin Otolaryngol 33:138-142. doi:10.1111/j.1749-4486. 2008.01676.x

23. Dudgeon D, King S, Howell D, Green E, Gilbert J, Hughes E et al (2012) Cancer Care Ontario's experience with implementation of routine physical and psychological symptom distress screening. Psychooncology 21:357-364. doi:10.1002/pon.1918

24. Zebrack B, Kayser K, Sundstrom L, Savas SA, Henrickson C, Acquati $\mathrm{C}$ et al (2015) Psychosocial distress screening implementation in cancer care: an analysis of adherence, responsiveness, and acceptability. J Clin Oncol 33:1165-1170. doi:10.1200/JCO.2014. 57.4020

25. Reicheld F, Markey R (2011) The Ultimate Question 2.0 (Revised and Expanded Edition): How Net Promoter Companies Thrive in a Customer-Driven World. Harvard Business School Press, p 224

26. Glasgow RE, Vogt TM, Boles SM (1999) Evaluating the public health impact of health promotion interventions: the RE-AIM framework. Am J Public Health 89:1322-1327

27. Cnossen IC, de Bree R, Rinkel RNPM, Eerenstein SEJ, Rietveld DHF, Doornaert P et al (2012) Computerized monitoring of patientreported speech and swallowing problems in head and neck cancer patients in clinical practice. Support Care Cancer 20:2925-2931. doi:10.1007/s00520-012-1422-y

28. Wall LR, Cartmill B, Ward EC, Hill AJ, Isenring E, Byrnes J et al (2016) "ScreenIT": computerized screening of swallowing, nutrition and distress in head and neck cancer patients during (chemo)radiotherapy. Oral Oncol 54:47-53. doi:10.1016/j.oraloncology. 2016.01.004

29. Stover A, Irwin DE, Chen RC, Chera BS, Mayer DK, Muss HB et al (2015) Integrating patient-reported outcome measures into routine cancer care: cancer patients' and clinicians' perceptions of acceptability and value. EGEMS (Washington, DC) 3:1169. doi:10. 13063/2327-9214.1169

30. Antunes B, Harding R, Higginson IJ (2014) Implementing patientreported outcome measures in palliative care clinical practice: a systematic review of facilitators and barriers. Palliat Med 28:158 175. doi:10.1177/0269216313491619

31. Boyce MB, Browne JP, Greenhalgh J (2014) The experiences of professionals with using information from patient-reported outcome measures to improve the quality of healthcare: a systematic review of qualitative research. BMJ Qual Saf 23:508-518. doi:10. 1136/bmjqs-2013-002524

32. Robinson JW, Roter DL (1999) Psychosocial problem disclosure by primary care patients. Soc Sci Med 48:1353-1362

33. Duman-Lubberding S, van Uden-Kraan CF, Jansen F, Witte BI, van der Velden LA, Lacko M et al (2016) Feasibility of an eHealth application "OncoKompas" to improve personalized survivorship cancer care. Support Care Cancer 24:2163-2171. doi:10.1007/ s00520-015-3004-2

34. Bush N, Donaldson G, Moinpour C, Haberman M, Milliken D, Markle V et al (2005) Development, feasibility and compliance of a web-based system for very frequent QOL and symptom home self-assessment after hematopoietic stem cell transplantation. Qual Life Res 14:77-93

35. Arnold CW, McNamara M, El-Saden S, Chen S, Taira RK, Bui AAT (2013) Imaging informatics for consumer health: towards a radiology patient portal. J Am Med Inform Assoc 20:1028-1036. doi:10.1136/amiajnl-2012-001457 